\title{
Simulating permeability reduction by clay mineral nanopores in a tight sandstone by combining computer $X$-ray microtomography and focussed ion beam scanning electron microscopy imaging
}

\author{
Arne Jacob ${ }^{1}$, Markus Peltz ${ }^{2}$, Sina Hale ${ }^{3}$, Frieder Enzmann ${ }^{1}$, Olga Moravcova ${ }^{1}$, Laurence N. Warr ${ }^{2}$, Georg Grathoff $^{2}$, \\ Philipp Blum ${ }^{3}$, and Michael Kersten ${ }^{1}$ \\ ${ }^{1}$ Geosciences Institute, Johannes Gutenberg-University, J.-J. Becherweg 21, 55099 Mainz, Germany \\ ${ }^{2}$ Institute of Geography and Geology, University Greifswald, Friedrich-Ludwig-Jahn-Str. 17a, 17487 Greifswald, Germany \\ ${ }^{3}$ Institute of Applied Geosciences (AGW), Karlsruhe Institute of Technology (KIT), \\ Kaiserstraße 12, 76131 Karlsruhe, Germany
}

Correspondence: Arne Jacob (a.jacob@uni-mainz.de)

Received: 9 September 2020 - Discussion started: 30 September 2020

Revised: 23 November 2020 - Accepted: 25 November 2020 - Published: 11 January 2021

\begin{abstract}
Computer X-ray microtomography ( $\mu \mathrm{XCT})$ represents a powerful tool for investigating the physical properties of porous rocks. While calculated porosities determined by this method typically match experimental measurements, computed permeabilities are often overestimated by more than 1 order of magnitude. This effect increases towards smaller pore sizes, as shown in this study, in which nanostructural features related to clay minerals reduce the permeability of tight reservoir sandstone samples. Focussed ion beam scanning electron microscopy (FIB-SEM) tomography was applied to determine the permeability effects of illites at the nanometre scale, and Navier-Stokes equations were applied to calculate the permeability of these domains. With these data, microporous domains (porous voxels) were defined using microtomography images of a tight reservoir sample. The distribution of these domains could be extrapolated by calibration against size distributions measured in FIB-SEM images. For this, we assumed a mean permeability for the dominant clay mineral (illite) in the rock and assigned it to the microporous domains within the structure. The results prove the applicability of our novel approach by combining FIB-SEM with X-ray tomographic rock core scans to achieve a good correspondence between measured and simulated permeabilities. This methodology results in a more accurate representation of reservoir rock permeability in comparison to that estimated purely based on $\mu \mathrm{XCT}$ images.
\end{abstract}

\section{Introduction}

Depositional environment and subsequent diagenetic alterations are two key factors that influence the bulk mineralogical composition and the authigenic clay mineral inventory of a reservoir (Wilson and Pittman, 1977; Worden and Morad, 1999), and therefore the fluid-flow properties of the porous rock. A well-established technique to image and analyse rapidly the $3 \mathrm{D}$ physical properties of porous rocks is computer X-ray microtomography $(\mu \mathrm{XCT})$ combined with the concept of digital rock physics (Andrä et al., 2013a, b; Okabe and Blunt, 2004). By applying monochromatic synchrotron radiation, it is possible to overcome conventional $\mu \mathrm{XCT}$ artefacts like beam hardening and problems that arise due to limited phase contrast, lack of resolution and edge preservation, as well as low signal-to-noise ratios (Brunke et al., 2008; Kling et al., 2018; Lindquist et al., 2000; Mayo et al., 2015; Spanne et al., 1994). Synchrotron-based $\mu$ XCT scans with image resolutions in the order of $1 \mu \mathrm{m}$ can provide a sound basis for flow and transport modelling of tight sandstones as suggested by Peng et al. (2014). They found that synchrotron $\mu \mathrm{XCT}$ imaging is necessary for tight sandstones when the connectivity of the pore space is low and pore throats cannot be resolved using a conventional $\mu \mathrm{XCT}$ scanner. They further concluded that a high abundance of the smallest resolvable pores falsifies modelled permeabilities due to an overestimation of actual pore sizes. Several studies have shown sub-micrometre pore structures to be a 
frequent feature of tight reservoir rocks (Jiang, 2012; Shah et al., 2016; Soulaine et al., 2016). Most of these nanostructures are related to different types of clay minerals; most commonly illite, kaolinite, chlorite and smectite (e.g. Wilson and Pittman, 1977; Worden and Morad, 1999; Desbois et al., 2016).

Although known for years, considering such structural features below $\mu \mathrm{XCT}$ resolution in pore-scale models remains challenging (Alyafei et al., 2015; Guan et al., 2019; Liu and Mostaghimi, 2018; Liu et al., 2020; Menke et al., 2019; Peng et al., 2012). Soulaine et al. (2016) systematically analysed the effect of sub-resolution domains with varying permeabilities on the simulated permeabilities of Berea sandstone (20 vol \% porosity, 2 vol \% sub-resolution domains) and found that calculated permeabilities can be reduced by up to $50 \%$, if microporous domain permeabilities converge towards zero. Thus, it is evident that neglecting sub-resolution information can lead to a significant overestimation of rock permeability in such simulations (e.g. Saxena et al., 2018, 2017). Menke et al. (2019) utilized a multi-scale Brinkman area approach, applying different permeabilities for each microporous domain to simulate flow in mono-mineralic carbonate rock. They showed that StokesBrinkman models are in good agreement with experimental data, whereas Stokes and/or Navier-Stokes models alone were not able to predict permeability in a conventional flow scenario. They also demonstrated that for pure carbonates, a direct correlation can be established between observed density contrasts and specific physical properties, such as porosity and permeability. However, this approach is not applicable in a system with more than one rock-forming mineral, such as a tight sandstone, where density contrasts relate to different mineral phases as well as sub-resolution porosities.

The lack of distinct material information for a voxel is often ascribed to the partial volume effect (e.g. Kessler et al., 1984; Ketcham and Carlson, 2001). To overcome the impact of this effect on physical properties of a rock, imaging techniques that can resolve the pore structure at different length scales have to be applied. For estimating the permeability of reservoir rocks, the resolution achieved by synchrotron radiation imaging lies within an acceptable range (Saxena et al., 2018). Several studies have demonstrated that, by combining X-ray and scanning electron imaging, the pore space of tight clay-bearing rocks can be spatially resolved from the millimetre down to the nanometre scale (e.g. Desbois et al., 2016; Hemes et al., 2015; Markussen et al., 2019).

In this study, we aim to demonstrate a new approach by combining synchrotron-based $\mu \mathrm{XCT}$ imaging with focussed ion beam scanning electron microscopy (FIB-SEM) to improve flow simulations in a tight sandstone formation with high clay mineral content. First, we used machine learningbased image segmentation to enhance pore space segmentations of artefact-rich FIB-SEM topologies. Then, we conducted Navier-Stokes simulations on FIB-SEM topologies. Finally, we subsequently used these simulations as input data for sub-resolution domains in $\mu$ XCT-based Stokes-Brinkman models (Brinkman, 1949; Neale and Nader, 1974). This novel morphology-based approach for sub-resolution-rich materials results in simulated permeabilities that fit experimental results significantly better than using Navier-Stokes simulations alone.

\section{Sample preparation and characterization}

In this study, a well-characterized illite-bearing Upper Rotliegend sandstone from Germany was used, which was sampled from the quarry Schwentesius near Bebertal village (Heidsiek et al., 2020). This well-known location exposes an analogue of the Permian gas reservoir sandstone of the Flechtingen High, which formed part of the North German Basin. Thin section analyses of this reservoir rock have shown that illite is the main clay mineral, which primarily occurs as a coating along detrital grains, illite meshworks grown on coatings, diagenetically altered K-feldspar and illitized lithoclasts (Fischer et al., 2012).

Samples were taken from a large sandstone block displaying a variety of different aeolian and fluvial depositional facies (Fig. 1a). We identified several facies denoted A to $\mathrm{J}$ from four different types of sedimentary depositional layers. The samples of the different facies were numbered from left to right. Samples were drilled out and extracted from marked locations in the form of plugs with a diameter of $2.5 \mathrm{~cm}$. The plugs were cut into three segments which were used for X-ray diffraction analyses, helium porosimetry measurements and FIB-SEM imaging. Mini plugs were drilled directly beside the plugs with a diameter of $3 \mathrm{~mm}$ and a length between 10 and $20 \mathrm{~mm}$. The larger plugs were used for mineralogical and geochemical analysis, and to measure permeabilities experimentally. The mini plugs were scanned at the synchrotron radiation-based $\mu \mathrm{XCT}$ imaging beamline P05 at the PETRA of DESY Hamburg (Germany). After the synchrotron measuring campaign, the mini plugs were additionally examined by FIB-SEM and energy dispersive X-ray spectroscopy (EDX) imaging to obtain qualitative and quantitative information about the clay mineral particles found within the rock pore space. Microporous structures in the Rotliegend sandstone sample could be resolved by comparing $\mu \mathrm{XCT}$ and FIB-SEM images. The term "microporous" refers to the definition of sub-micrometre porosity by Soulaine et al. (2016), who differentiated between void, solid and microporous voxels in $\mu$ XCT images. According to for example Tinet et al. (2020), the term "nanoporous" is used to describe structures with predominant pore sizes in the nanometre range $(0.2-1000 \mathrm{~nm})$. In this range, the clay minerals often appear as a greyish pore-filling phase in $\mu \mathrm{XCT}$ images. 
(a)

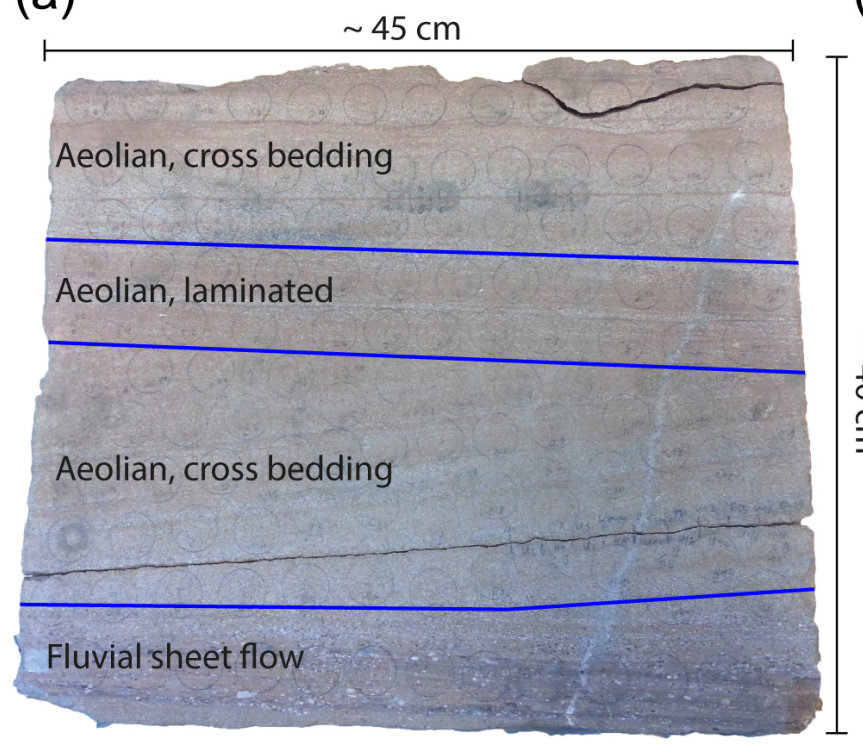

(b)

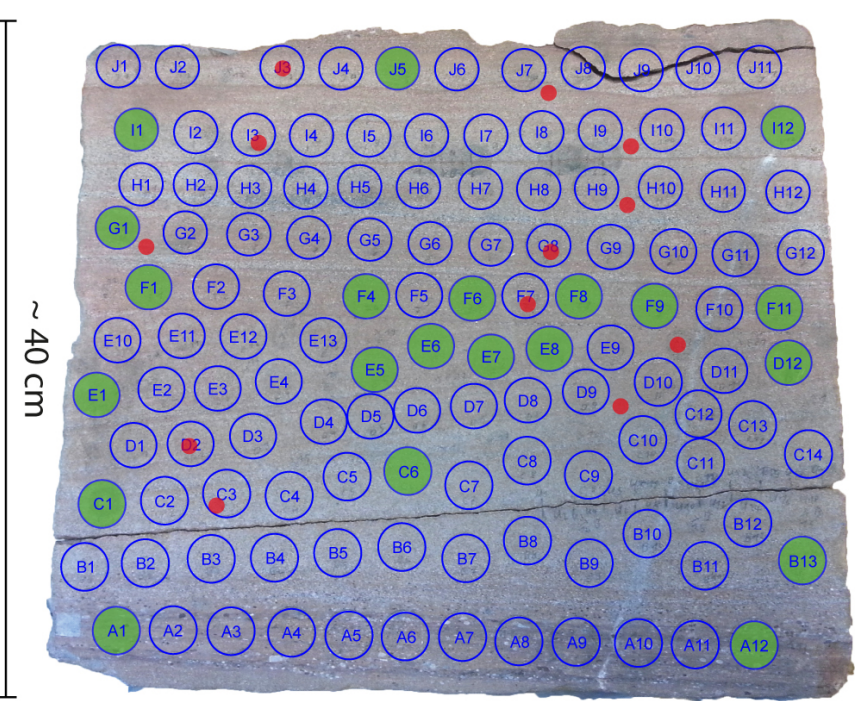

Figure 1. (a) Upper Rotliegend sandstone block showing four main deposition facies. (b) Sampling locations and sizes of the extracted plugs (green) and the mini plugs (red) extracted.

\section{Analytical procedures}

\subsection{Mineralogical characterization}

X-ray diffraction analyses using the Rietveld analysis program Profex 4.0 (Doebelin and Kleeberg, 2015; Ufer et al., 2012) have shown a homogenous mineralogical composition along the layers of the sample block with only slight variations in content (Fig. 2).

The main components are quartz (58 wt \%-69 wt \%), authigenic and diagenetic feldspars $(12 \mathrm{wt} \%-20 \mathrm{wt} \%)$, calcite $(1 \mathrm{wt} \%-18 \mathrm{wt} \%)$, and illite (10 wt $\%-17 \mathrm{wt} \%)$. In the $<0.2 \mu \mathrm{m}$ size fraction, we observed traces of swelling smectite interpreted as contaminants from surface weathering. Accessory hematite and barite particles also occur with abundances of $<1 \mathrm{wt} \%$. In the Bebertal tight sandstone, illite is by far the most abundant clay mineral and makes up $\sim 95 \mathrm{wt} \%$ of the $<2 \mu \mathrm{m}$ fraction. Commonly, the nanometre-scale microstructural features of reservoir rocks containing significant amounts of clay minerals are usually not detectable at $\mu \mathrm{XCT}$ resolution due to a low absorption contrast (Ahmad et al., 2018).

\subsection{Permeability measurements and pore size distribution}

A helium gas-driven permeameter under steady-state conditions was used to experimentally obtain permeability values for the individual plugs (e.g. Filomena et al., 2014). Compressed air was used to apply a pressure of $10 \mathrm{bar}$ to the core samples that were coated by a latex membrane. A Bronkhorst F-111C-RBB-33-V was used as a flowmeter. It was cali- brated by polynomial calibration and has a measuring accuracy of $\pm 0.5 \%$ plus $\pm 0.1 \%$ of the full scale. To measure the differential pressure, an Emerson Rosemount 3051S Ultra was used with an accuracy of $\pm 0.045 \%$. To control the inflow and outflow, two pressure sensors (Brooks 5866) with an accuracy of $\pm 0.5 \%$ were installed. For permeability measurements, the inflow and outflow pressures of the helium flux were sequentially increased in up to six pressure steps. The differential pressure was kept constant at 200-500 mbar depending on the sample properties. The intrinsic sample permeability was derived from the apparent gas permeability, $K_{\mathrm{g}}$, determined for each pressure step using Darcy's law (Liu et al., 2017):

$K_{\mathrm{g}}=\frac{2 Q p_{2} \eta L}{A\left(p_{1}^{2}-p_{2}^{2}\right)}$,

where $Q$ is the measured gas flow rate, $\eta$ is the dynamic viscosity of the permeant, $L$ is the sample length, $A$ is the sample cross section, and $p_{1}$ and $p_{2}$ are the inflow and outflow pressures. By plotting $K_{\mathrm{g}}$ against $\frac{1}{\left(p_{1}+p_{2}\right) / 2}$, the data can be fitted by a straight line. The intercept of the bestfit line at the $K_{\mathrm{g}}$ axis corresponds to the intrinsic sample permeability, $K_{\text {int }}$ (Gao and Li, 2016; Klinkenberg, 1941). Also, MICP measurements were conducted with an Autopore IV Series (Micromeritic Instrument Corp.) to determine the pore size distribution of a dried sub-sample with a weight of $\sim 2.5 \mathrm{~g}$, which was taken from a cross-bedded aeolian layer of the sandstone block. Based on the capillary law, MICP enables the analysis of a wide spectrum of pore sizes ( $3 \mathrm{~nm}$ to $>900 \mu \mathrm{m}$ ), corresponding to a pressure range of 0 $414 \mathrm{MPa}$. As a non-wetting liquid with a high contact angle 


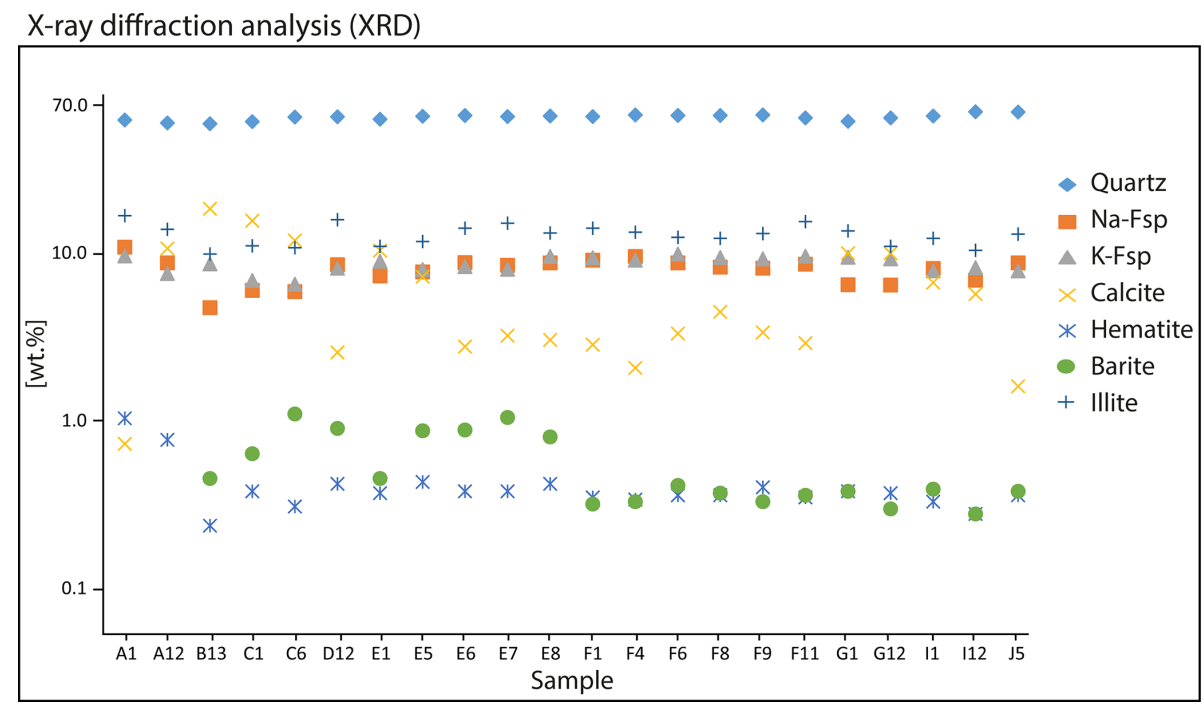

Figure 2. XRD analysis of the main minerals in the plugs based on Rietveld calculations, determined for several samples of facies A to $\mathrm{J}$ of the sandstone block.

$\left(130-140^{\circ}\right)$, mercury only penetrates a pore when pressure is applied. Under the assumption of cylindrical pores, the applied pressure is directly proportional to the pore throat diameter as described by the Washburn equation (Washburn, 1921):

$D=\frac{-4 \gamma \cdot \cos \theta}{P}$,

where $D$ is pore throat diameter, $\gamma$ is the surface tension, $\theta$ is the contact angle and $P$ is the applied pressure.

\subsection{Synchrotron-based $\mu \mathrm{XCT}$}

For synchrotron tomography, a beam energy of $29.87 \mathrm{KeV}$ was used while the sample-detector distance was $1.2 \mathrm{~cm}$. The effective image resolution of the detector equipped with a CCD camera was $1.22 \mu \mathrm{m}$ per pixel, while the image size was $3056 \times 3056$ pixels. We used an advanced reconstruction script described in Moosmann et al. (2014) with the MATLAB ${ }^{\circledR}$ software and binned the images by a factor of 2 before reconstruction to increase the signal-to-noise ratio. This decreased the voxel resolution to $2.43 \mu \mathrm{m}$ and changed the image size to $1528 \times 1528$ pixels. The number of projections was 1200 , with the information of five subsequent images used to calculate an average for every projection image. After reconstruction of the 3D image stacks, the scans were denoised using the non-local means filter of the GeoDict 2020 software package (Buades et al., 2011). Image segmentation of the mini plugs was realized by conventional greyscale thresholding. The greyscale values for each phase on a 16 bit intensity range were $0-8550$ for pores, $8551-$ 12880 for grains, $12881-25000$ for cements and 2500165535 for high-density cements and oxides. Since the best threshold values for each phase varied slightly from sam- ple to sample, these values were adjusted for each segmentation within a small range of \pm 50 . A qualitative comparison with machine learning segmentation revealed a better poreto-solid segmentation and resolving of small pore throats by thresholding (Fig. 3). Since the main goal was to achieve the best possible permeability estimation, the differentiation between pore and solid is more important for permeability estimation than the accurate segmentation into different phases (Khan et al., 2016). Leu et al. (2014) point out that even a small variation in pore throat morphology can have a large impact on the estimation of permeability.

For permeability simulations, we either used the fast Fourier transformation (SIMPLE-FFT) or the left-identityright (LIR) solvers, both implemented in the FlowDict module of the GeoDict software package (Linden et al., 2015; Moulinec and Suquet, 1995). While the SIMPLE-FFT solver is fast for calculating low-porosity domains, the LIR solver is better suited for high-porosity domains and requires less memory. Both iterative finite volume solvers can apply Navier-Stokes and Navier-Stokes-Brinkman equations. Derived from these equations, Darcy's law (Eq. 1) is used to calculate the permeability of a material (Darcy, 1856):

$\boldsymbol{u}=-\frac{K}{\eta}(\nabla p-\boldsymbol{f})$.

In Eq. (3), $\boldsymbol{u}$ is the three-dimensional average fluid-flow velocity, $K$ is the permeability, $\eta$ is the fluid viscosity, $p$ is the intrinsic average pressure tensor and $f$ is the force density field, which was defined using the Navier-Stokes conservation of momentum equation for all three dimensions (Eq. 4):

$-\eta \Delta \boldsymbol{u}+(\boldsymbol{u} \cdot \nabla) \boldsymbol{u}+\nabla p=\boldsymbol{f}$.

The Brinkman term can be added to the Navier-Stokes equation where porous voxels are required. These voxels include 


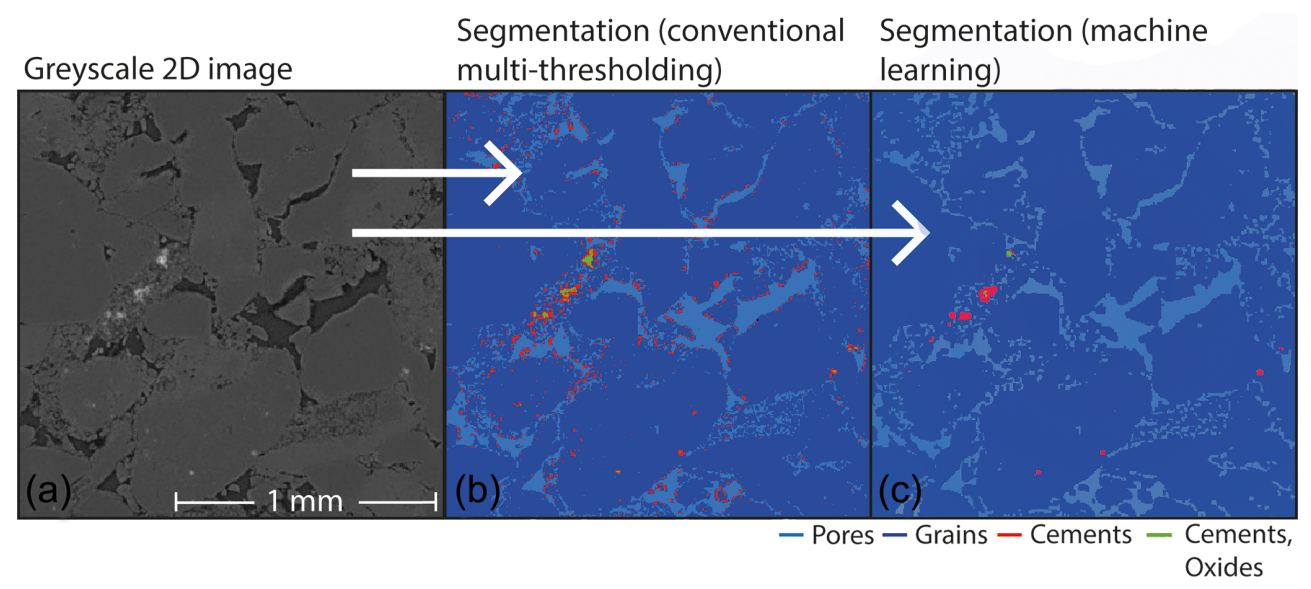

Figure 3. (a) Greyscale 2D $\mu \mathrm{XCT}$ image of a mini plug. (b) Segmented phases using multi thresholding. (c) Segmented phases using the machine learning image classification module of the software ilastik (Version 1.3.3) by Berg et al. (2019).

the nanoporous flow resistivity:

$-\eta \Delta \boldsymbol{u}+(\boldsymbol{u} \cdot \nabla) \boldsymbol{u}+\eta K^{-1} \boldsymbol{u}+\nabla p=\boldsymbol{f}$,

where $K^{-1}$ is the inverse of the permeability tensor and $\eta K^{-1}$ the flow resistivity. The applicability and robustness of combining Navier-Stokes equations with the Brinkman term has been validated by Iliev and Laptev (2004).

We calculated the permeability with symmetric boundary conditions in tangential and flow direction with a pressure drop of $20370 \mathrm{~Pa}$. The symmetric boundary conditions are valid for low-porosity structures with non-periodic pore throat geometries. The differential pressure value was set to be able to compare the results with helium permeation flux measurements where similar values have been used. As a convergence stopping criterion, a low error bound of 0.05 was chosen. The error bound criterion uses the result of a previous iteration to predict the final solution by linear and quadratic extrapolation. This stops the iteration when the relative difference regarding the prediction is smaller than $5 \%$. During this process, the solver recognizes oscillations and local minima or maxima which prevents a premature stopping of the solver during the iteration process.

\subsection{FIB-SEM measurements}

In this study, a Zeiss Auriga crossbeam electron microscope equipped with a Gemini electron column and an Orsay Physics ion beam was used. SEM images were taken at $1 \mathrm{kV}$ with an in-lens secondary electron (SE2) detector, and FIB slicing was executed with a beam current between 0.5 and $2 \mathrm{nA}$ and a voltage of $30 \mathrm{kV}$. This resulted in a slice thickness of $25 \mathrm{~nm}$. A large FOV of $\sim 20 \mu \mathrm{m}$ could be reached. To derive structural information from the FIB-SEM images, extensive post-processing of the data was required. Following image alignment and cropping, stripes and shadow artefacts were filtered out before image segmentation. The Slice
Alignment operation of the module ImportGeo of the GeoDict 2020 software package was used to align the images, while the Curtaining Filter was used for stripes correction (Fig. 4). In general, the segmentation of pores in FIB-SEM images was not straightforward since scans of porous polished sections are pseudo-2D and contain information from behind the actual imaging plane (De Boever et al., 2015).

As multi-thresholding and watershed segmentation algorithms have problems with shine-through artefacts (Prill et al., 2013), capturing the correct 3D pore space geometry is of crucial importance for the determination of a realistic permeability. Recent advances have shown that machine learning image segmentation software can successfully be utilized to segment pore space in CT scans (Berg et al., 2018).

The software ilastik, an interactive learning and segmentation toolkit by Berg et al. (2019), was used for the interactively supervised machine learning segmentation of the phases in our FIB-SEM images (Fig. 4). The built-in pixel classification module groups the probability of each pixel to be assigned to a phase according to their different imaged features. The software provides a set of different images based on features derived from the original image (filtering and smoothing, edge detection, etc.). Examples of the correct class (phase) provided by the user builds a decision surface in feature space. Based on these features, a random forest classifier assigns each pixel or voxel to a certain phase. This method works for both 2D and 3D data. The accuracy of this method increases with the number of user-provided training data. In a manually controlled workflow, it was possible to reach high segmentation accuracies with only minor over- or underestimations of the pore space (Fig. 4c, d).

\subsection{Defining microporous domains}

The need to define microporous domains results from the mismatch of permeability between $\mu \mathrm{XCT}$ simulations and gas-driven permeameter tests. While the simulation of per- 


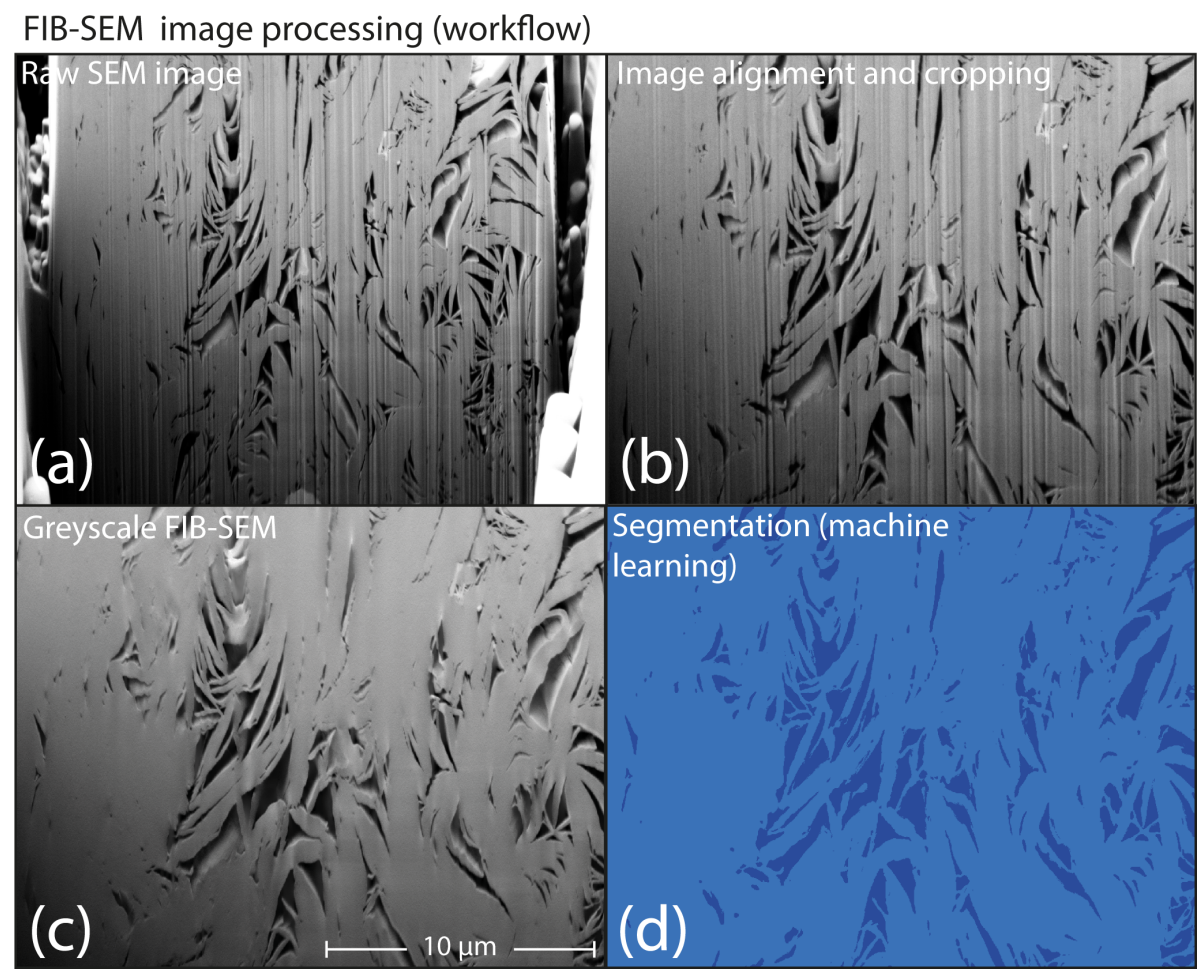

Figure 4. (a) Raw SEM image of secondary illite growth in a porous feldspar with streaks and shadow artefacts. (b) Images with aligned slices of a cropped region of interest. (c) Filtered greyscale SEM image of the illite meshworks. (d) The binarized result after image segmentation with pixel classification algorithms of the software ilastik.

meability in structures with high permeability and porosity obtained by $\mu \mathrm{XCT}$ scans is precise, the effect of nanoporosity below resolution on permeability increases with decreasing permeability (Pittman and Thomas, 1979; Saxena et al., 2018). When comparing backscattered electron (BSE) images with $\mu \mathrm{XCT}$ images of the same slice, it becomes apparent that the smallest pores in $\mu \mathrm{XCT}$ images simplify the real pore structure (Fig. 5). Furthermore, SEM and EDX images revealed that most of the pores are filled with clay minerals. Since both void and microporous regions share similar greyscale values, it is impossible to correctly differentiate upon segmentation. In this approach, the segmentation of the pores includes clay minerals with a low absorption contrast. To determine the distribution of illite in $\mu$ XCT scans, we used correlative $\mu$ XCT, SEM and EDX measurements. For this, a $3 \mathrm{~mm}$ plug was embedded into epoxy resin and then ground and polished until the region of interest was reached. Two sites were chosen for EDX mappings (Fig. 5). Comparing EDX mappings with CT images shows that the distribution of illite agrees with the textural findings of Fischer et al. (2012).

Furthermore, it becomes apparent that illite enrichments coincide with regions that are usually referred to as void pore space in $\mu \mathrm{XCT}$ images. The mismatch between real pore structure and segmented pore space is highest in small pores and throats. An average size of $\sim 5 \mu \mathrm{m}$ was measured for illites which cover the surfaces of the quartz and feldspar grains. This corresponds to approximately two voxels in the $\mu X C T$ images. To refine flow and reduce the influence of overestimated pore sizes in these specific regions, we define all pores with a diameter $\leq 2$ voxels as microporous domains. The Brinkman term accounts for small pores, where grains are porous themselves (Brinkman, 1949). To extract these regions from the initial pore space segmentation $F_{p *}$ we calculated Euclidian distance maps as used by Maurer et al. (2003):

$d=\sqrt{\left(x_{2}-x_{1}\right)+\left(y_{2}-y_{1}\right)+\left(z_{2}-z_{1}\right)}$,

where $d$ is the distance between two points; $x_{1}, y_{1}$ and $z_{1}$ are the coordinates of the first point; and $x_{2}, y_{2}$ and $z_{2}$ are the coordinates of the second point. By selecting $d(\leq 2)$ all pore voxels with the nearest distance of $\leq 2$ voxels to the next solid surface are masked, including the outer rim of larger pores (Fig. 6b). To obtain a mask with pores $\leq 2$ voxels, this rim layer surplus must be removed. This was realized by performing a morphological dilation operation on $d(>2)$ using a structure element SE2 of $2^{3}$ voxels. By subtracting the dilated image from $d(>2)$, the microporous domain data $F_{\mu 2}$ (Fig. 6c) can be obtained.

$F_{\mu 2}=d(\leq 2)-\delta_{\mathrm{SE} 2}(d(>2))$ 


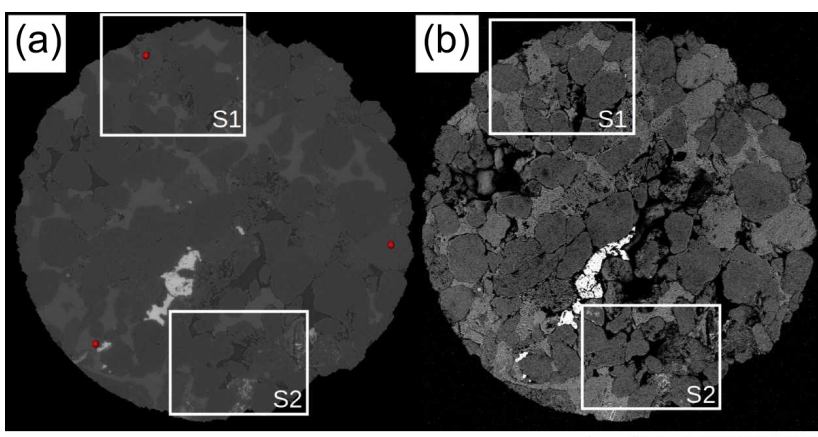

(c)

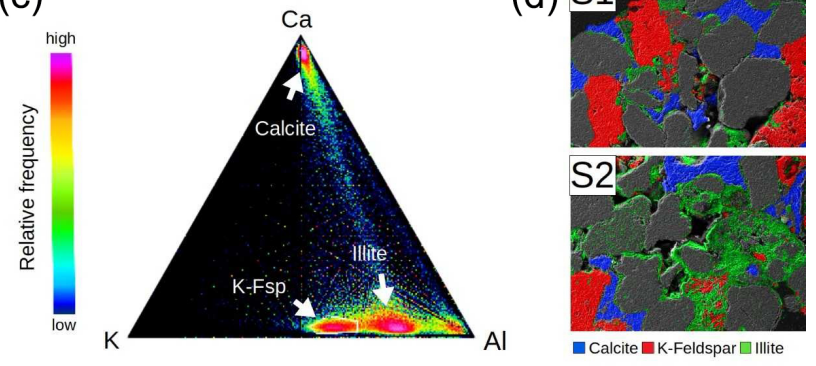

Figure 5. (a) $\mu \mathrm{XCT}$ and corresponding (b) BSE image of the polished section including the close-up regions S1 and S2 that were used for EDX mapping to analyse the distribution of illites. (c) Ternary plot of $\mathrm{Ca}, \mathrm{K}$ and $\mathrm{Al}$ content of each pixel in the mappings. Calcite, illite and $\mathrm{K}$-feldspar plot in three distinct regions. By selecting these areas, a phase map overlay was created that visualizes the location of these phases in SE images. (d) Region S1 and S2 with phase map overlays. Illite is predominantly found in the vicinity of altered feldspars, as coating along grain boundaries and as authigenic pore filling.

In GeoDict the permeabilities of the microporous domains are calculated with the Brinkman term. Based on flow simulations on 3D FIB-SEM images of illite meshworks, an isotropic permeability was assigned to the microporous domains (Fig. 6). Yoon and Dewers (2013) confirmed the validity of the approach of extrapolating structural features of clays measured by FIB-SEM to the pore scale. The complete workflow for a precise permeability simulation is illustrated in Fig. 7.

\section{Results and discussion}

\subsection{Permeability measurements and pore size distribution}

Four to six pressure stages were applied to the plug samples to determine their gas permeability. In Table 1, parameters which were used for the permeameter test are shown for sample F8. These values yield a Klinkenberg factor of 0.56 and a quadratic regression coefficient of 0.94 .

Overall, the measured intrinsic permeabilities range between 1.1 and $5.4 \mathrm{mD}$ with an average value of $2.9 \mathrm{mD}$ for both aeolian facies (Table 2; Fig. 1, sample series E and F). The quadratic regression coefficient ranges from 0.732 to 0.998 , which indicates a high accuracy of the permeameter test. The small variation of the physical rock properties between the main layers is induced by different angles of the grain layering in each plug sample and small-scale variations in grain and pore size distributions. The observed variance is in the typical range of observed permeability fluctuations for tight reservoir sandstones (Lis-Śledziona, 2019). Considering the observed permeability, the studied rock samples are at the lower end of the permeability range known for sedimentary reservoir rocks (Gluyas and Swarbrick, 2004).

The pore size distribution of the sub-sample analysed by mercury intrusion porosimetry (Sect. 3.2) was obtained by a semi-logarithmic representation of the normalized intrusion volume achieved per pressure interval (Fig. 8). The consumed capillary stem intrusion volume of $27 \%$ was within the acceptable range needed for precise measurements. We discovered a major peak at approximately $1 \mu \mathrm{m}$, representing the most common pore throat diameter.

In addition to the mercury porosimetry results, calculations of the pore size distribution of FIB-SEM and $\mu \mathrm{XCT}$ mini plug images were conducted using the GeoDict module PoroDict. This module provides an algorithm that virtually pushes spheres of different sizes into a medium to determine the 3D pore size distribution (Münch and Holzer, 2008). FIBSEM measurements of the pore size distribution cover the small pores related to the illite nanoporosity, while $\mu \mathrm{XCT}$ porosimetry illustrates the pore size distribution of the largerscale intergranular pore space skeleton.

The $\mu \mathrm{XCT}$ pore volume analysis shows a constant rise towards the smallest observed pore diameters (2.44 $\mu \mathrm{m}$; Fig. 9). The steepest slope is observed between 7.3 and $12.2 \mu \mathrm{m}$, which indicates that the largest volume of pore bodies is observed in that range. The calculated pore size distribution from nanoporous 3D structures of illite meshworks obtained by FIB-SEM imaging shows three distinct peaks at 75, 125 and $250 \mathrm{~nm}$. This illustrates that the most common inscribed pore diameters are relatively small compared to the actual extent of the pores, which is considered typical for slit-shaped pore systems where the pore axial ratio is high (Desbois et al., 2016). Ultimately, this results from the different thicknesses of clay platelets and heterogeneity in the alignment of the illite nanostructure (Aplin et al., 2006).

An apparent gap exists between diameters observed by MICP and 3D imaging with FIB-SEM and $\mu$ XCT. While MICP peaks at around $1 \mu \mathrm{m}$, diameters observed by $\mu \mathrm{XCT}$ start at $2.4 \mu \mathrm{m}$ and the largest inscribed diameters observed by FIB-SEM are below $700 \mathrm{~nm}$. However, it must be noted that pressure-controlled MICP generally gives information about the dimension of pore throats, whereas pore size distributions provided by imaging techniques give information about pore body volumes (Zhao et al., 2015). Furthermore, pore shielding may cause an underestimation of larger pores for MICP (Abell et al., 1999; Gane et al., 2004). The occur- 


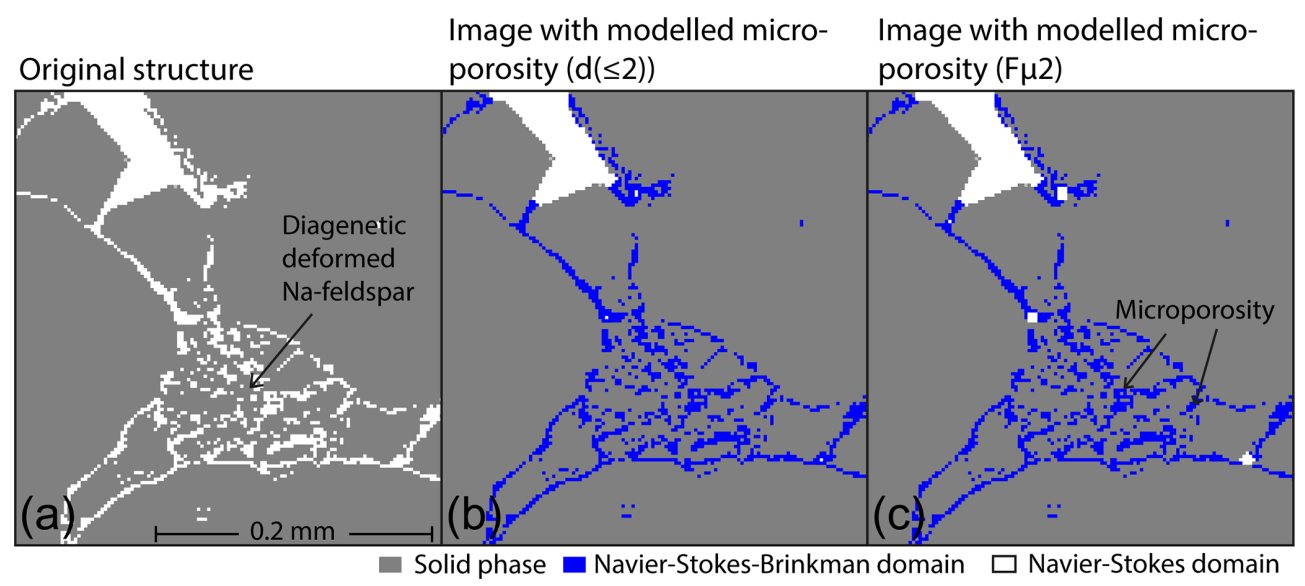

Figure 6. (a) Segmented $\mu \mathrm{XCT}$ image of the pore space of a mini plug. (b) Image with applied microporous domain using the Euclidian distance map approach. (c) Image with removed outer rim layer of larger pores.

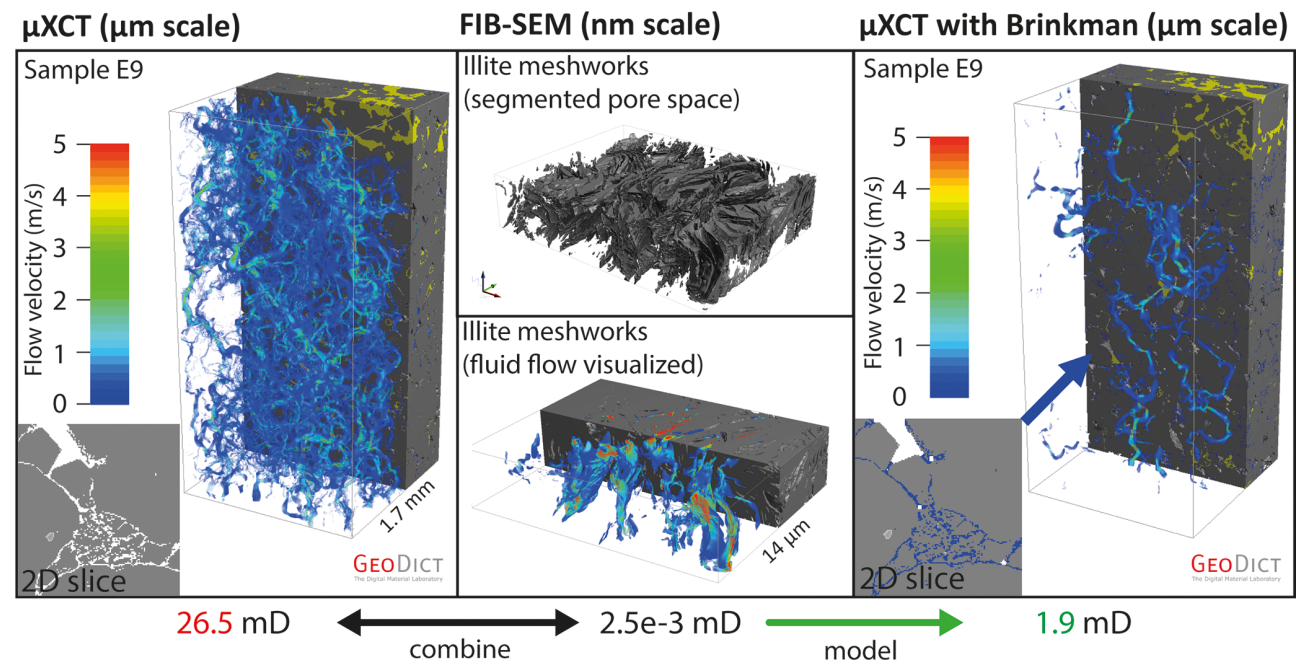

Figure 7. Workflow for microporous domain modelling combining FIB-SEM nanoporosity with $\mu$ XCT scans. Sample E9 of the aeolian layer with well-distributed flow paths was selected for visualization. Upon the modelling of the microporous domains, the total fluid-flow velocity decreases. Displayed simulated permeabilities include the mean values of five samples with the best distribution of percolation paths. Fluid-flow velocities close to zero are transparent.

rence of authigenic illites is the likely cause of this effect as they are commonly found in pore throat areas. Since the Washburn equation assumes ideal pore throats of cylindrical shape, the underestimation of larger pores becomes more evident with the increasing complexity of the pore throat system at both the millimetre and nanometre scale (Washburn, 1921). Therefore, a direct comparison between the used methods is unlikely to result in compatible results.

\subsection{Permeability simulation}

A calculated isotropic permeability of $2.53 \times 10^{-3} \mathrm{mD}$ was used for the microporous domains based on the NavierStokes fluid-flow simulations of permeability of FIB-SEM scans of the illite meshworks. The number of porous vox- els resulting from clay mineral modelling ranges between $3.3 \mathrm{vol} \%$ and $7.1 \mathrm{vol} \%$ of the total structure volume for all $\mu \mathrm{XCT}$ scans considered. A comparison of the modelled clay minerals in $\mu \mathrm{XCT}$ scans with XRD mass balancing highlights a large difference between the mineral abundances measured (Table 3, Fig. 2).

While the mean amount of clay minerals based on XRD measurements was $12.7 \mathrm{wt} \%$ (about 11.3 vol\% within a structure with $8 \%$ porosity), an average amount of $5.4 \mathrm{vol} \%$ was modelled by the distance map algorithm. This is expected since the illite content inside grains was not modelled since it has no effect on permeability. We simulated permeability of 12 mini plug samples that were scanned by $\mu$ XCT and compared them with measurements from gas permeameter experiments. As a first step, we extracted and illustrated 
Table 1. Parameters of the gas permeameter flux experiment (sample F8), including measured helium gas flow rate, recorded inflow and outflow pressures as well as calculated apparent gas permeability for each pressure stage. For evaluating the intrinsic sample permeability, the sample cross section $(0.025 \mathrm{~m})$ and length $(0.05 \mathrm{~m})$ as well as the dynamic viscosity of helium $\left(18.4 \times 10^{-6} \mathrm{Pas}\right)$ is also needed.

\begin{tabular}{lrrrr}
\hline $\begin{array}{l}\text { Pressure } \\
\text { stage }\end{array}$ & $\begin{array}{r}\text { Inflow } \\
\text { pressure }(\mathrm{Pa})\end{array}$ & $\begin{array}{r}\text { Outflow } \\
\text { pressure }(\mathrm{Pa})\end{array}$ & $\begin{array}{r}\text { Flow rate } \\
\left(\mathrm{m}^{3} \mathrm{~s}^{-1}\right)\end{array}$ & $\begin{array}{r}\text { Apparent } \\
\text { permeability }(\mathrm{mD})\end{array}$ \\
\hline 1 & 129522.3 & 109151 & $2.8803 \mathrm{e}-08$ & 2.38 \\
2 & 149587.1 & 129167.9 & $2.8401 \mathrm{e}-08$ & 2.38 \\
3 & 174634.9 & 154120.4 & $2.7072 \mathrm{e}-08$ & 2.28 \\
4 & 224581.7 & 204228.1 & $2.5041 \mathrm{e}-08$ & 2.16 \\
5 & 324516.8 & 304066.2 & $2.4409 \mathrm{e}-08$ & 2.13 \\
\hline
\end{tabular}

Table 2. Intrinsic permeabilities and porosities of the measured sandstone plug samples.

\begin{tabular}{cccccccccccc}
\hline & E5 & E6 & E7 & E8 & E13 & F4 & F6 & F8 & F9 & Mean & $\begin{array}{c}\text { Standard } \\
\text { deviation }( \pm 1 \sigma)\end{array}$ \\
\hline Permeability (mD) & 1.1 & 5.1 & 5.4 & 2.2 & 4.2 & 2.3 & 2.3 & 1.9 & 1.4 & 2.9 & 1.5 \\
\hline
\end{tabular}

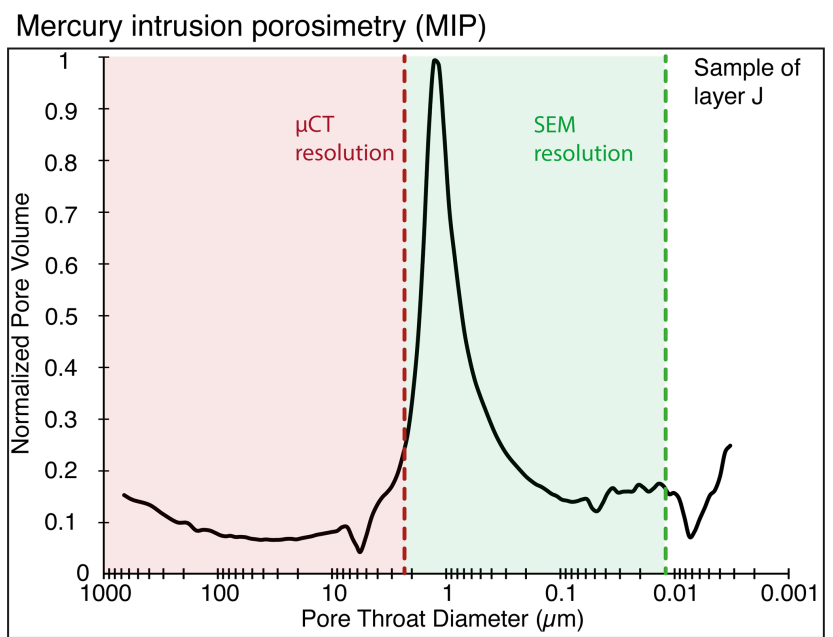

Figure 8. Distribution of the pore throat diameters of a sample of the aeolian facies in layer $\mathbf{J}$ obtained from mercury intrusion porosimetry (MICP).

the 10 largest and 100 largest open flow paths through the pore space of all mini plug cores before the modelling of the microporous domains (Fig. 10). This yields information concerning the heterogeneity of the flow fields and allows the validity of the Navier-Stokes simulations to be checked. Structures with flow impingement often cause numerical problems, which results in an artificial underestimation of the permeability simulations. Significant underestimations of permeability after clay mineral modelling were also found in areas where the percolation paths in the samples were limited to a few voxels in the structure before modelling.

This effect leads to an artificial permeability drop, which renders calculations less precise. Since evenly distributed flow paths are necessary to determine the true permeability

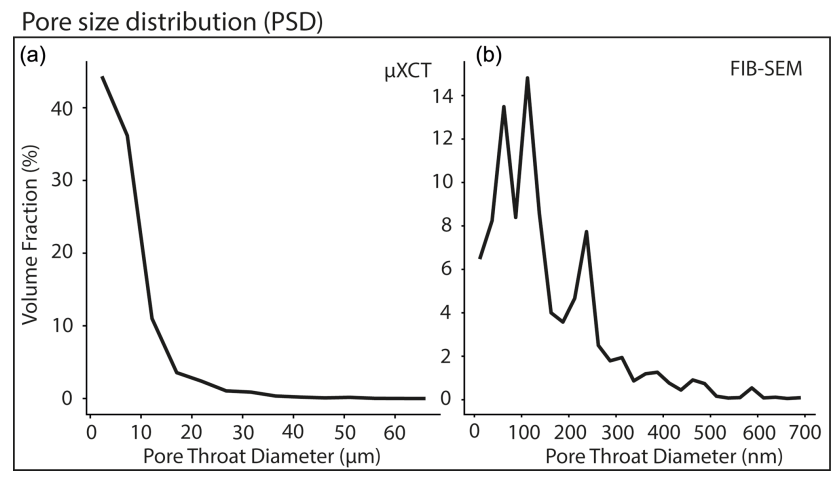

Figure 9. Pore throat diameters from $\mu \mathrm{XCT}$ (a) and FIB-SEM images (b).

of a volume of a rock, we considered only permeability calculations of samples which show no flow impingement for modelling (Bear, 1972; Leu et al., 2014; Zhang et al., 2000). The validity of the simulations was ensured by applying the variance algorithm on the flow fields discussed in Jacob et al. (2019).

The mean value of the experimentally obtained intrinsic gas permeabilities was $2.9 \mathrm{mD}$ (Table 2, Fig. 11a). Samples with no flow impingement had an initial mean permeability of $26.5 \mathrm{mD}$, whereas the mean permeability simulated on $\mu \mathrm{XCT}$ images was $26.5 \mathrm{mD}$ (Fig. 11b). With applied microporous domains, a mean permeability of $1.9 \mathrm{mD}$ was calculated (Fig. 11c).

The mismatch between measured and simulated permeabilities could be decreased to $1 \mathrm{mD}(-34.5 \%)$ compared to $23.6 \mathrm{mD}(+813.8 \%)$ prior to the modelling. Hence, our approach significantly improved the match between measured and simulated permeabilities and lies within the standard deviation of the permeabilities measured by the gas permeame- 
Table 3. Modelled clay mineral content within the microporous domains in $\mu$ XCT scans.

\begin{tabular}{lllllllllllllll}
\hline & C3 & D2 & D9 & E9 & F7 & G2 & G8 & H9 & I3 & I9 & J3 & J7 & $\begin{array}{c}\text { Mean } \\
\text { Standard } \\
\text { deviation }( \pm 1 \sigma)\end{array}$ \\
\hline Clay mineral content (vol \%) & 4.7 & 3.3 & 5.0 & 5.4 & 7.1 & 5.0 & 6.0 & 6.3 & 4.1 & 6.2 & 6.2 & 6.1 & 5.4 & 1.0 \\
\hline
\end{tabular}

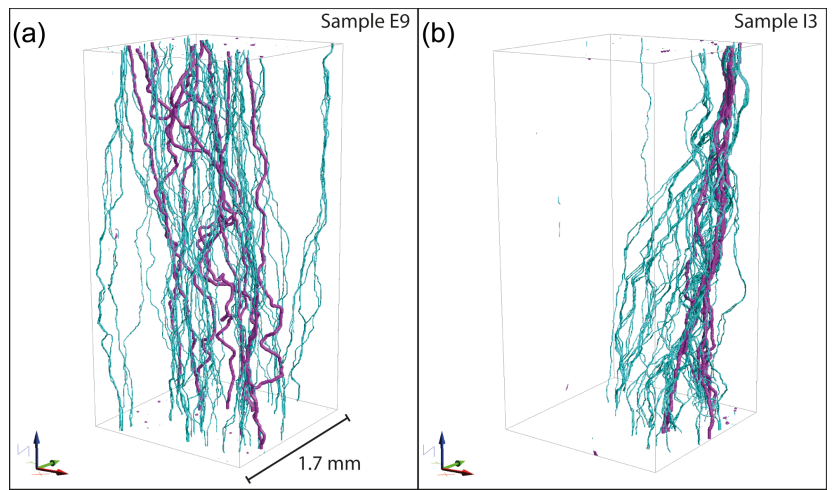

Figure 10. Comparison of percolation paths in two $\mu \mathrm{XCT}$ reconstructions of the 3D imaging data without microporous domain modelling. (a) Well distributed percolation paths in a $\mu \mathrm{XCT}$ reconstruction of mini plug sample E9 without microporous domain modelling. (b) Constricted percolation paths with flow impingement limited to a small region of the structure in mini plug sample I3 without microporous domain modelling. The 10 largest percolation paths are coloured in purple; the 100 largest percolation paths are coloured in cyan.

ter (Table 2). Histograms of the simulated fluid-flow velocities indicate a strong decrease in velocities due to the modelling of the microporous domains in sample E9 (Fig. 12). Correlation histograms of the velocities depict differences induced by the modelling. While identical fluid-flow field velocities would plot as a single straight line, the velocities, in this case, show straight lines with varying slopes. This indicates a general decrease in the fluid-flow velocities with a splitting of different flow path velocities. Points which plot as a line represent a main fluid-flow path with a direct correlation of the velocities between the original and the modelled structure's flow field. Furthermore, a wider spread of the distribution of high velocities results from microporous domain modelling. This indicates narrow pore throats where fluid-flow velocities are locally enhanced compared to the structure before the modelling.

Based on our combined analytical and numerical study, further research may help to increase the accuracy of simulated permeabilities even further. Since isotropic permeabilities of the microporous domains were applied to $\mu \mathrm{XCT}$ images, the accuracy can be improved by taking the anisotropy of clay mineral fabrics and surface topology into account. This can be done by applying anisotropic permeabilities in the calculation of the microporous domains. While this study

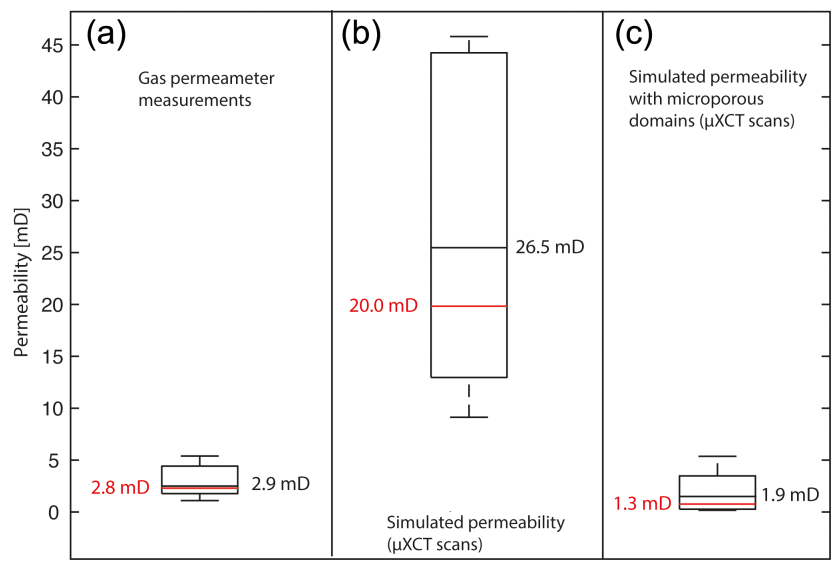

Figure 11. Comparison of measured and simulated permeabilities. The boxes indicate the upper and lower quartile of derived permeability values. Median values are coloured in red; mean values are coloured in black. (a) Measured permeabilities using the gas permeameter test. (b) Simulated permeabilities using $\mu \mathrm{XCT}$ data. (c) Simulated permeabilities using $\mu \mathrm{XCT}$ data with modelled microporous domains.

showed a good match between the experimental and simulated permeability, the need to include heterogeneities of clay mineral layering to improve the simulations was depicted in Villiéras et al. (1997).

The presented approach might also be applicable to other rock types such as mudrocks, carbonates, etc., if the preconditions are met. The examined rock properties (e.g. permeability) should be based on the same scale dependencies as the rock analysed in this work (e.g. Grathoff et al., 2016).

\section{Conclusions}

Overall, the outcome of this study shows that combining $\mu \mathrm{XCT}$ and FIB-SEM imaging with numerical models constitutes a valuable and novel approach for determining physical properties of clay-bearing tight reservoir rocks. Considering the high number of accessible pores in the scans, the phenomenon of flow impingement was mainly attributed to the unresolvable nanoporosity. While permeability, which is one of the most important reservoir properties, is often determined by simulations based on $\mu$ XCT scans of small samples taken from a field-scale reservoir, we were able to demonstrate that an accurate estimation for clay-rich and low-permeability rocks is only possible if nanoscale poros- 


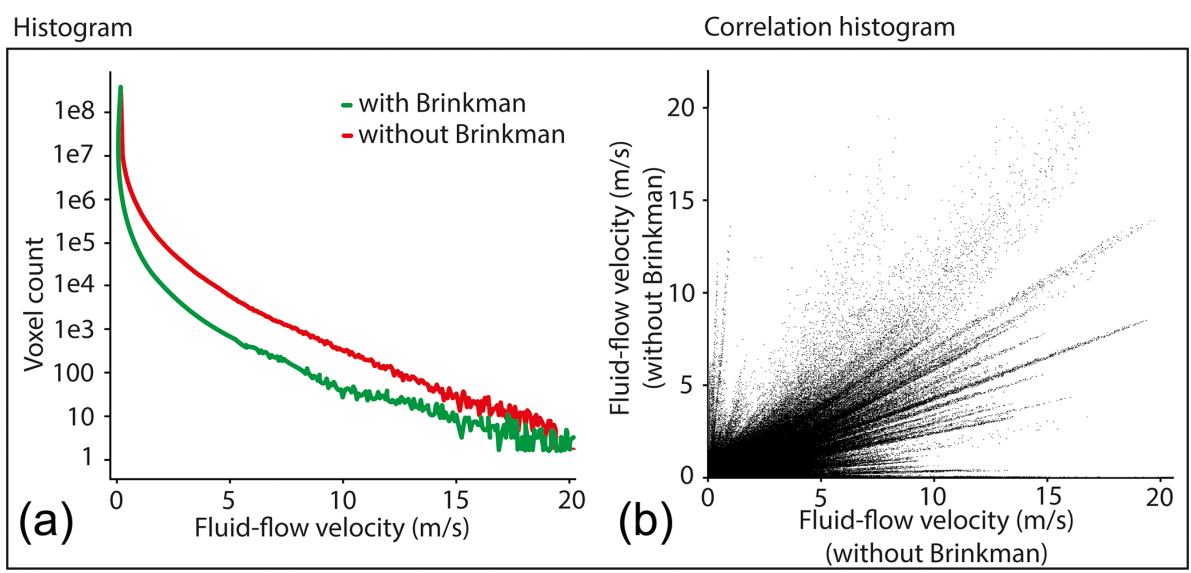

Figure 12. Comparison of unmodelled $\mu \mathrm{XCT}$ images and modelled microporous domain images (a). Correlation histogram prior to and after the modelling that shows a decrease in the main fluid-flow velocities, while few velocities after the modelling were increased with a wide spread of distribution (b).

ity is also included. Thus, our simulations using the Euclidian distance map approach resulted in an improved match with stationary gas permeameter measurements in contrast to permeability simulations merely based on unmodified $\mu \mathrm{XCT}$ images. Adopting this multi-method approach, we increased the accuracy of simulated permeabilities of samples measured by $\mu \mathrm{XCT}$. These results have important implications for improved modelling of reservoirs relevant to gas and water applications. A realistic simulated permeability of a tight reservoir sandstone could only be achieved by appropriate modelling of the nanoporosity related to matrix clay minerals (illite) that occur below the $\mu \mathrm{XCT}$ resolution. The simulated permeability based on combined $\mu \mathrm{XCT}$ and FIBSEM images and modelled microporous domains showed good agreement with the experimental results. Obtaining an even distribution of the simulated fluid-flow paths through the sample without flow impingement was necessary to obtain an accurate permeability estimation from 3D imaging. Resolving the nanopore structure and distribution of clay mineral-related features by the combined analytical and numerical modelling approach represents a tool for achieving a more accurate understanding of the fluid-flow behaviour within tight sandstones, with direct relevance to predicting the injection, storage or extraction of gas or water in a reservoir rock. Our multi-method approach can be applied to determine more accurate permeability values and flow paths for reservoir rocks with high clay mineral content if direct experimental measurements are not successful. Hence, future studies should focus on distinguishing the different morphologies of clay minerals and their related anisotropic effect on rock permeability. The permeability of the nanoporous structures depends highly on the layering of the clays and their spatial orientation on the grain surfaces and within feldspars. This approach should include a variety of various sedimentological facies, also with high porosity and permeability, to inves- tigate whether clay mineral modelling is also a valid tool for such sedimentary rocks.

Data availability. Data can be partially accessed upon request by Arne Jacob, Markus Peltz and Frieder Enzmann.

Supplement. The supplement related to this article is available online at: https://doi.org/10.5194/se-12-1-2021-supplement.

Author contributions. The conceptualization was developed by AJ, MP, SH, FE, LNW, GG, PB and MK. The process methodology was developed by AJ and MP. The software was provided by FE while the programming was conducted by AJ and MP. The final validation of the results was done by AJ, MP, SH, FE, LNW, GG, PB and MK. Formal analysis was executed by AJ and MP. The review and editing was executed by AJ, MP, SH, FE, OM, LNW, GG, PB and MK. The visualization of the results was conducted by $\mathrm{AJ}$ and MP. Supervision was provided by FE, LNW, GG, PB and MK. The project was administrated by FE, LNW, GG, PB and MK.

Competing interests. The authors declare that they have no conflict of interest.

Acknowledgements. This work was supported by the German Federal Ministry of Education and Research (BMBF) "Geological Research for Sustainability (GEO:N)" program, which is part of the BMBF "Research for Sustainable Development (FONA3)" framework program. It is part of the project ResKin (Reaction kinetics in reservoir rocks, 03G0871E). We would like to thank Fabian Wilde and the staff of PETRA synchrotron facility at DESY Hamburg for their assistance with the imaging beamline P05. Jens Hornung and Meike Hintze from the TU Darmstadt are also acknowledged for 
providing us with gas permeability measurements of the studied samples.

Financial support. This research has been supported by the German Federal Ministry of Education and Research (BMBF) (grant no. 03G0871E).

This open-access publication was funded by Johannes Gutenberg University Mainz.

Review statement. This paper was edited by Florian Fusseis and reviewed by two anonymous referees.

\section{References}

Abell, A. B., Willis, K. L., and Lange, D. A.: Mercury Intrusion Porosimetry and Image Analysis of CementBased Materials, J. Colloid Interf. Sci., 211, 39-44, https://doi.org/10.1006/jcis.1998.5986, 1999.

Ahmad, K. M., Kristaly, F., and Docs, R.: Effects of clay mineral and physico-chemical variables on sandstone rock permeability, J. Oil Gas Petrochem. Sci., 1, 18-26, https://doi.org/10.30881/jogps.00006, 2018.

Alyafei, N., Raeini, A. Q., Paluszny, A., and Blunt, M. J.: A Sensitivity Study of the Effect of Image Resolution on Predicted Petrophysical Properties, Transp. Porous. Med., 110, 157-169, https://doi.org/10.1007/s11242-015-0563-0, 2015.

Andrä, H., Combaret, N., Dvorkin, J., Glatt, E., Han, J., Kabel, M., Keehm, Y., Krzikalla, F., Lee, M., Madonna, C., Marsh, M., Mukerji, T., Saenger, E. H., Sain, R., Saxena, N., Ricker, S., Wiegmann, A., and Zhan, X.: Digital rock physics benchmarks-Part I: Imaging and segmentation, Comput. Geosci., 50, 25-32, https://doi.org/10.1016/j.cageo.2012.09.005, 2013a.

Andrä, H., Combaret, N., Dvorkin, J., Glatt, E., Han, J., Kabel, M., Keehm, Y., Krzikalla, F., Lee, M., Madonna, C., Marsh, M., Mukerji, T., Saenger, E. H., Sain, R., Saxena, N., Ricker, S., Wiegmann, A., and Zhan, X.: Digital rock physics benchmarkspart II: Computing effective properties, Comput. Geosci., 50, 3343, https://doi.org/10.1016/j.cageo.2012.09.008, 2013b.

Aplin, A. C., Matenaar, I. F., McCarty, D. K., and van der Pluijm, B. A.: Influence of mechanical compaction and clay mineral diagenesis on the microfabric and pore-scale properties of deepwater Gulf of Mexico mudstones, Clay. Clay. Miner., 54, 500514, https://doi.org/10.1346/CCMN.2006.0540411, 2006.

Bear, J.: Dynamics of fluids in porous media, American Elsevier Pub. Co, New York, 1972.

Berg, S., Saxena, N., Shaik, M., and Pradhan, C.: Generation of ground truth images to validate micro-CT image-processing pipelines, Leading Edge, 37, 412-420, https://doi.org/10.1190/tle37060412.1, 2018.

Berg, S., Kutra, D., Kroeger, T., Straehle, C. N., Kausler, B. X., Haubold, C., Schiegg, M., Ales, J., Beier, T., Rudy, M., Eren, K., Cervantes, J. I., Xu, B., Beuttenmueller, F., Wolny, A., Zhang, C., Koethe, U., Hamprecht, F. A., and Kreshuk, A.: ilastik: interactive machine learning for (bio)image analysis, Nat. Methods, https://doi.org/10.1038/s41592-019-0582-9, 2019.
Brinkman, H. C.: Calculations on the flow of heterogeneous mixtures through porous media, Appl. Sci. Res., 1, 333, https://doi.org/10.1007/BF02120339, 1949.

Brunke, O., Brockdorf, K., Drews, S., Müller, B., Donath, T., Herzen, J., and Beckmann, F.: Comparison between x-ray tubebased and synchrotron radiation-based $\mu C T$, edited by: Stock, $S$. R., San Diego, California, USA., 2008.

Buades, A., Coll, B., and Morel, J.-M.: Non-Local Means Denoising, Image Processing On Line, 1, 208-212, https://doi.org/10.5201/ipol.2011.bcm_nlm, 2011.

Darcy, H.: Les Fontaines Publiques de la Ville de Dijon, Les Fontaines Publiques de la Ville de Dijon: Exposition et Application des Principes a Suivre et des Formulesa Employer dans les Questions de Distribution d'Eau, Dalmont, 1856.

De Boever, W., Derluyn, H., Van Loo, D., Van Hoorebeke, L., and Cnudde, V.: Data-fusion of high resolution X-ray CT, SEM and EDS for 3D and pseudo-3D chemical and structural characterization of sandstone, Micron, 74, 15-21, https://doi.org/10.1016/j.micron.2015.04.003, 2015.

Desbois, G., Urai, J. L., Hemes, S., Schröppel, B., Schwarz, J.O., Mac, M., and Weiel, D.: Multi-scale analysis of porosity in diagenetically altered reservoir sandstone from the Permian Rotliegend (Germany), J. Petrol. Sci. Eng., 140, 128-148, https://doi.org/10.1016/j.petrol.2016.01.019, 2016.

Doebelin, N. and Kleeberg, R.: Profex?: a graphical user interface for the Rietveld refinement program BGMN, J. Appl. Crystallogr., 48, 1573-1580, https://doi.org/10.1107/S1600576715014685, 2015.

Filomena, C. M., Hornung, J., and Stollhofen, H.: Assessing accuracy of gas-driven permeability measurements: a comparative study of diverse Hassler-cell and probe permeameter devices, Solid Earth, 5, 1-11, https://doi.org/10.5194/se-5-1-2014, 2014.

Fischer, C., Dunkl, I., Von Eynatten, H., Wijbrans, J. R., and Gaupp, R.: Products and timing of diagenetic processes in Upper Rotliegend sandstones from Bebertal (North German Basin, Parchim Formation, Flechtingen High, Germany), Geol. Mag., 149, 827-840, https://doi.org/10.1017/S0016756811001087, 2012.

Gane, P. A. C., Ridgway, C. J., Lehtinen, E., Valiullin, R., Furó, I., Schoelkopf, J., Paulapuro, H., and Daicic, J.: Comparison of NMR Cryoporometry, Mercury Intrusion Porosimetry, and DSC Thermoporosimetry in Characterizing Pore Size Distributions of Compressed Finely Ground Calcium Carbonate Structures, Ind. Eng. Chem. Res., 43, 7920-7927, https://doi.org/10.1021/ie049448p, 2004.

Gao, H. and Li, H. A.: Pore structure characterization, permeability evaluation and enhanced gas recovery techniques of tight gas sandstones, J. Nat. Gas Sci. Eng., 28, 536-547, https://doi.org/10.1016/j.jngse.2015.12.018, 2016.

Gluyas, J. G. and Swarbrick, R. E.: Petroleum geoscience, Blackwell Pub, Malden, MA, USA, 2004.

Grathoff, G. H., Peltz, M., Enzmann, F., and Kaufhold, S.: Porosity and permeability determination of organic-rich Posidonia shales based on 3-D analyses by FIB-SEM microscopy, Solid Earth, 7, 1145-1156, https://doi.org/10.5194/se-7-1145-2016, 2016.

Guan, K. M., Nazarova, M., Guo, B., Tchelepi, H., Kovscek, A. R., and Creux, P.: Effects of Image Resolution on Sandstone Porosity and Permeability as Obtained from X-Ray Microscopy, Transp. 
Porous. Med., 127, 233-245, https://doi.org/10.1007/s11242018-1189-9, 2019.

Heidsiek, M., Butscher, C., Blum, P., and Fischer, C.: Small-scale diagenetic facies heterogeneity controls porosity and permeability pattern in reservoir sandstones, Environ. Earth Sci., 79, 425, https://doi.org/10.1007/s12665-020-09168-z, 2020.

Hemes, S., Desbois, G., Urai, J. L., Schröppel, B., and Schwarz, J.-O.: Multi-scale characterization of porosity in Boom Clay (HADES-level, Mol, Belgium) using a combination of X-ray $\mu-C T$, 2D BIB-SEM and FIBSEM tomography, Micropor. Mesopor. Mat., 208, 1-20, https://doi.org/10.1016/j.micromeso.2015.01.022, 2015.

Iliev, O. and Laptev, V.: On numerical simulation of flow through oil filters, Comput. Visual. Sci., 6, 139-146, https://doi.org/10.1007/s00791-003-0118-8, 2004.

Jacob, A., Enzmann, F., Hinz, C., and Kersten, M.: Analysis of Variance of Porosity and Heterogeneity of Permeability at the Pore Scale, Transp. Porous. Med., 130, 867-887, https://doi.org/10.1007/s11242-019-01342-7, 2019.

Jiang, S.: Clay Minerals from the Perspective of Oil and Gas Exploration, in: Clay Minerals in Nature - Their Characterization, Modification and Application, edited by: Valaskova, M., IntechOpen, 2012.

Kessler, R. M., Ellis, J. R., and Eden, M.: Analysis of Emission Tomographic Scan Data: Limitations Imposed by Resolution and Background, J. Comput. Assist. Tomo., 8, 514-522, https://doi.org/10.1097/00004728-198406000-00028, 1984.

Ketcham, R. A. and Carlson, W. D.: Acquisition, optimization and interpretation of X-ray computed tomographic imagery: applications to the geosciences, Comput. Geosci., 27, 381-400, https://doi.org/10.1016/S0098-3004(00)00116-3, 2001.

Khan, F., Enzmann, F., and Kersten, M.: Multi-phase classification by a least-squares support vector machine approach in tomography images of geological samples, Solid Earth, 7, 481-492, https://doi.org/10.5194/se-7-481-2016, 2016.

Kling, T., Vogler, D., Pastewka, L., Amann, F., and Blum, P.: Numerical Simulations and Validation of Contact Mechanics in a Granodiorite Fracture, Rock. Mech. Rock. Eng., 51, 2805-2824, https://doi.org/10.1007/s00603-018-1498-x, 2018.

Klinkenberg, L. J.: The permeability of porous Media to liquids and gases, Drilling and Production Practice, API-41-200, 1941.

Leu, L., Berg, S., Enzmann, F., Armstrong, R. T., and Kersten, M.: Fast X-ray Micro-Tomography of Multiphase Flow in Berea Sandstone: A Sensitivity Study on Image Processing, Transp. Porous. Med., 105, 451-469, https://doi.org/10.1007/s11242014-0378-4, 2014.

Linden, S., Wiegmann, A., and Hagen, H.: The LIR space partitioning system applied to the Stokes equations, Graphical Models, 82, 58-66, https://doi.org/10.1016/j.gmod.2015.06.003, 2015.

Lindquist, W. B., Venkatarangan, A., Dunsmuir, J. and Wong, T.: Pore and throat size distributions measured from synchrotron X-ray tomographic images of Fontainebleau sandstones, J. Geophys. Res., 105, 21509-21527, https://doi.org/10.1029/2000JB900208, 2000.

Lis-Śledziona, A.: Petrophysical rock typing and permeability prediction in tight sandstone reservoir, Acta Geophys., 67, 18951911, https://doi.org/10.1007/s11600-019-00348-5, 2019.

Liu, G., Bai, Y., Fan, Z., and Gu, D.: Determination of Klinkenberg Permeability Conditioned to Pore-Throat
Structures in Tight Formations, Energies, 10, 1575, https://doi.org/10.3390/en10101575, 2017.

Liu, M. and Mostaghimi, P.: Reactive transport modelling in dual porosity media, Chem. Eng. Sci., 190, 436-442, https://doi.org/10.1016/j.ces.2018.06.005, 2018.

Liu, M., Starchenko, V., Anovitz, L. M., and Stack, A. G.: Grain detachment and transport clogging during mineral dissolution in carbonate rocks with permeable grain boundaries, Geochem. Cosmochim. Ac., 280, 202-220, https://doi.org/10.1016/j.gca.2020.04.022, 2020.

Markussen, Ø., Dypvik, H., Hammer, E., Long, H., and Hammer, $\varnothing .: 3 \mathrm{D}$ characterization of porosity and authigenic cementation in Triassic conglomerates/arenites in the Edvard Grieg field using 3D micro-CT imaging, Mar. Petrol. Geol., 99, 265-281, https://doi.org/10.1016/j.marpetgeo.2018.10.015, 2019.

Maurer, C. R., Rensheng, Q., and Raghavan, V.: A linear time algorithm for computing exact Euclidean distance transforms of binary images in arbitrary dimensions, IEEE T. Pattern Anal., 25, 265-270, https://doi.org/10.1109/TPAMI.2003.1177156, 2003.

Mayo, S., Josh, M., Nesterets, Y., Esteban, L., Pervukhina, M., Clennell, M. B., Maksimenko, A., and Hall, C.: Quantitative micro-porosity characterization using synchrotron micro-CT and xenon K-edge subtraction in sandstones, carbonates, shales and coal, Fuel, 154, 167-173, https://doi.org/10.1016/j.fuel.2015.03.046, 2015.

Menke, H., Gao, Y., Linden, S., and Andrew, M.: Using nanoXRM and high-contrast imaging to inform micro-porosity permeability during Stokes-Brinkman single and two-phase flow simulations on micro-CT images, preprint, EarthArXiv, https://doi.org/10.31223/osf.io/ubg6p, 2019.

Moosmann, J., Ershov, A., Weinhardt, V., Baumbach, T., Prasad, M. S., LaBonne, C., Xiao, X., Kashef, J., and Hofmann, R.: Timelapse $\mathrm{X}$-ray phase-contrast microtomography for in vivo imaging and analysis of morphogenesis, Nat. Protoc., 9, 294-304, https://doi.org/10.1038/nprot.2014.033, 2014.

Moulinec, H. and Suquet, P.: A FFT-Based Numerical Method for Computing the Mechanical Properties of Composites from Images of their Microstructures, in: IUTAM Symposium on Microstructure-Property Interactions in Composite Materials, edited by: Pyrz, R., Springer Netherlands, Dordrecht, 235-246, 1995.

Münch, B. and Holzer, L.: Contradicting Geometrical Concepts in Pore Size Analysis Attained with Electron Microscopy and Mercury Intrusion, J. Am. Ceram. Soc., 91, 4059-4067, https://doi.org/10.1111/j.1551-2916.2008.02736.x, 2008.

Neale, G. and Nader, W.: Practical significance of brinkman's extension of darcy's law: Coupled parallel flows within a channel and a bounding porous medium, Can. J. Chem. Eng., 52, 475-478, https://doi.org/10.1002/cjce.5450520407, 1974.

Okabe, H. and Blunt, M. J.: Prediction of permeability for porous media reconstructed using multiple-point statistics, Phys. Rev. E, 70, 066135, https://doi.org/10.1103/PhysRevE.70.066135, 2004.

Peng, S., Hu, Q., Dultz, S., and Zhang, M.: Using X-ray computed tomography in pore structure characterization for a Berea sandstone: Resolution effect, J. Hydrol., 472-473, 254-261, https://doi.org/10.1016/j.jhydrol.2012.09.034, 2012.

Peng, S., Marone, F., and Dultz, S.: Resolution effect in X-ray microcomputed tomography imaging and small pore's contribution 
to permeability for a Berea sandstone, J. Hydrol., 510, 403-411, https://doi.org/10.1016/j.jhydrol.2013.12.028, 2014.

Pittman, E. D. and Thomas, J. B.: Some Applications of Scanning Electron Microscopy to the Study of Reservoir Rock, J. Petrol. Tech., 31, 1375-1380, https://doi.org/10.2118/7550-PA, 1979.

Prill, T., Schladitz, K., Jeulin, D., Faessel, M., and Wieser, C.: Morphological segmentation of FIB-SEM data of highly porous media, J. Microsc.-Oxford, 250, 77-87, https://doi.org/10.1111/jmi.12021, 2013.

Saxena, N., Hofmann, R., Alpak, F. O., Berg, S., Dietderich, J., Agarwal, U., Tandon, K., Hunter, S., Freeman, J., and Wilson, O. B.: References and benchmarks for porescale flow simulated using micro-CT images of porous media and digital rocks, Adv. Water Resour., 109, 211-235, https://doi.org/10.1016/j.advwatres.2017.09.007, 2017.

Saxena, N., Hows, A., Hofmann, R., O. Alpak, F., Freeman, J., Hunter, S., and Appel, M.: Imaging and computational considerations for image computed permeability: Operating envelope of Digital Rock Physics, Adv. Water Resour., 116, 127-144, https://doi.org/10.1016/j.advwatres.2018.04.001, 2018.

Shah, S. M., Gray, F., Crawshaw, J. P., and Boek, E. S.: Microcomputed tomography pore-scale study of flow in porous media: Effect of voxel resolution, Adv. Water Resour., 95, 276-287, https://doi.org/10.1016/j.advwatres.2015.07.012, 2016.

Soulaine, C., Gjetvaj, F., Garing, C., Roman, S., Russian, A., Gouze, P., and Tchelepi, H. A.: The Impact of Sub-Resolution Porosity of X-ray Microtomography Images on the Permeability, Transp. Porous. Med., 113, 227-243, https://doi.org/10.1007/s11242016-0690-2, 2016.

Spanne, P., Thovert, J. F., Jacquin, C. J., Lindquist, W. B., Jones, K. W., and Adler, P. M.: Synchrotron Computed Microtomography of Porous Media: Topology and Transports, Phys. Rev. Lett., 73, 2001-2004, https://doi.org/10.1103/PhysRevLett.73.2001, 1994.

Tinet, A.-J., Corlay, Q., Collon, P., Golfier, F., and Kalo, K.: Comparison of various $3 \mathrm{D}$ pore space reconstruction methods and implications on transport properties of nanoporous rocks, Adv. Water Resour., 141, 103615, https://doi.org/10.1016/j.advwatres.2020.103615, 2020.
Ufer, K., Kleeberg, R., Bergmann, J., and Dohrmann, R.: Rietveld Refinement of Disordered Illite-Smectite Mixed-Layer Structures by a Recursive Algorithm. II: Powder-Pattern Refinement and Quantitative Phase Analysis, Clay. Clay. Miner., 60, 535552, https://doi.org/10.1346/CCMN.2012.0600508, 2012.

Villiéras, F., Michot, L. J., Bardot, F., Cases, J. M., François, M. and Rudziński, W.: An Improved Derivative Isotherm Summation Method To Study Surface Heterogeneity of Clay Minerals $\dagger$, Langmuir, 13, 1104-1117, https://doi.org/10.1021/la9510083, 1997.

Washburn, E. W.: The Dynamics of Capillary Flow, Phys. Rev., 17, 273-283, https://doi.org/10.1103/PhysRev.17.273, 1921.

Wilson, M. D. and Pittman, E. D.: Authigenic Clays in Sandstones: Recognition and Influence on Reservoir Properties and Paleoenvironmental Analysis, J. Sediment. Res., 47, 3-31, https://doi.org/10.1306/212F70E5-2B24-11D78648000102C1865D, 1977.

Worden, R. H. and Morad, S.: Clay Minerals in Sandstones: Controls on Formation, Distribution and Evolution, in Clay Mineral Cements in Sandstones, edited by: Worden, R. H. and Morad, S., Blackwell Publishing Ltd., Oxford, UK, 1-41, 1999.

Yoon, H. and Dewers, T. A.: Nanopore structures, statistically representative elementary volumes, and transport properties of chalk: NANOPORE STRUCTURES, SREV, AND FIB-SEM, Geophys. Res. Lett., 40, 4294-4298, https://doi.org/10.1002/grl.50803, 2013.

Zhang, D., Zhang, R., Chen, S., and Soll, W. E.: Pore scale study of flow in porous media: Scale dependency, REV, and statistical REV, Geophys. Res. Lett., 27, 1195-1198, https://doi.org/10.1029/1999GL011101, 2000.

Zhao, H., Ning, Z., Wang, Q., Zhang, R., Zhao, T., Niu, T., and Zeng, Y.: Petrophysical characterization of tight oil reservoirs using pressure-controlled porosimetry combined with rate-controlled porosimetry, Fuel, 154, 233-242, https://doi.org/10.1016/j.fuel.2015.03.085, 2015. 